\title{
Prevalence, Purposes, and Perceived Effectiveness of Complementary and Alternative Medicine Use in a Hypertension Population: A Questionnaire Survey
}

\author{
Huanhuan Hu, ${ }^{1}$ Gang Li, ${ }^{2}$ Jiali Duan, ${ }^{3}$ and Takashi Arao ${ }^{4}$ \\ ${ }^{1}$ Lab of Exercise Epidemiology, Graduate School of Sport Sciences, Waseda University, Saitama 3591192, Japan \\ ${ }^{2}$ Institute of Chronic Diseases Control and Prevention, Beijing Center for Diseases Control and Prevention, Beijing 100013, China \\ ${ }^{3}$ Institute of School Health, Beijing Center for Diseases Control and Prevention, Beijing 100013, China \\ ${ }^{4}$ Lab of Exercise Epidemiology, Faculty of Sport Sciences, Waseda University, Saitama 3591192, Japan
}

Correspondence should be addressed to Takashi Arao; tarao@waseda.jp

Received 4 October 2013; Accepted 28 November 2013

Academic Editors: I. Grotto, W. Kirch, and A. Rosano

Copyright (C) 2013 Huanhuan Hu et al. This is an open access article distributed under the Creative Commons Attribution License, which permits unrestricted use, distribution, and reproduction in any medium, provided the original work is properly cited.

\begin{abstract}
Complementary and alternative medicine (CAM) is widely used among patients with hypertension. This study aimed to determine the use of CAM in community-dwelling individuals with hypertension. A cross-sectional questionnaire survey was administered to 318 hypertension patients to examine prevalence and patterns of CAM use; the use of CAM, specifically for treatment of hypertension or other conditions, and perceived effectiveness of CAM were examined. CAM use in the last 12 months was reported by $236(74.2 \%)$ participants. Only $13.1 \%$ of these CAM users reported using CAM to treat hypertension. CAM users did not differ statistically from non-CAM users by age, marital status, health status, duration of hypertension, income, or education. Females showed a significantly higher prevalence of CAM use than that of males (OR 1.82, 95\% CI 1.09, 3.11). Family/relatives, doctors, and patients themselves were the three main sources of information about CAM. More than $70 \%$ of responses were able to perceive the effectiveness of alternative medical systems, mind-body medicine, and manipulative/body-based therapies. There was a high prevalence of CAM use among hypertension patients, although the majority of CAM use was not specifically for hypertension. Further research is needed to assess the safety and efficacy of diverse CAM.
\end{abstract}

\section{Background}

Hypertension is a major public health challenge worldwide because of its high prevalence and concomitant risks of cardiovascular disease $[1,2]$. The prevalence of hypertension in China has been rising rapidly during the last 30 years. Recent studies revealed the prevalence of hypertension in people aged 35 and older may reach $30 \%$ or more, while the societal response is fragmented with low levels of awareness, treatment, and control $[3,4]$.

Self-care plays an important role in the management of blood pressure, as recommended by the Joint National Committee on Prevention, Detection, Evaluation, and Treatment of High Blood Pressure (JNC7) [5]. In recent years, complementary and alternative medicine (CAM) as a form of self-care has been a growing area of health care, especially in developed countries [6, 7]. The use of CAM has increased significantly in Australia, UK, and the USA over the past decade [8-11]. Some studies have shown a higher prevalence of CAM use among women, persons with greater wealth and higher educational status, and patients with chronic disease [12-15].

Various forms of CAM are available in China, such as tai Chi, qigong, traditional Chinese medicine, and acupuncture. These CAMs are widely used by Chinese to promote general health and to treat or prevent medical conditions. The report of WHO Traditional Medicine Strategy 2002-2005 stated that the prevalence of CAM use might be $40 \%$ in China [16]. Some of the CAMs such as Tai Chi, Qigong, and traditional Chinese medicine and herbs have been reported to have 
beneficial effects on blood pressure [17-19]. A study showed that $14 \%$ of those with a history of hypertension reported having used complementary or alternative treatments for their hypertension [20]. However, that study does not include any further information about the complementary or alternative treatments used.

CAM use in hypertension patients has been reported in the USA [21], the UK [22], and Singapore [23], and some other studies have focused on CAM use in patients with cardiovascular disease $[24,25]$. According to these reports, there seems to be a high prevalence of CAM use in hypertension patients for treatment of hypertension or other medical conditions. A survey conducted in the USA reported that $69.5 \%$ of hypertension patients aged 65 years or older used at least one form of CAM [21]. Most of these studies reported the prevalence of CAM use in hypertension patients and examined the association between CAM use and demographic features. However, few studies reported the perceived effectiveness of, source of information about, and introduction to CAM in hypertension patients [26].

To date, there is little published literature on the use of CAM in hypertension patients in China $[16,20]$. Understanding the use of CAM among hypertension patients is important to the safety of public consumption and the integration of CAM treatments into mainstream medicine. It can also provide more information regarding the ways in which hypertension patients cope with blood pressure control. The current study aimed to investigate (1) the prevalence and patterns of CAM use among hypertension patients, (2) the use of CAM specifically for treatment of hypertension or other conditions, and (3) the perceived effectiveness of CAM use.

\section{Methods}

A face-to-face questionnaire was used to obtain self-report data on CAM use in a hypertension population. This survey was designed to provide some primary data about selfcare ability, which is important with regard to further development of intervention programs for self-care. This questionnaire survey was conducted in a local community in Beijing, China.

2.1. Sample Size. The target sample size was 327 individuals, based on the following assumptions: prevalence of CAM use (55\%), an allowable error of $10 \%$, a confidence level of $95 \%$, and power of $80 \%$. An assumed $10 \%$ dropout rate translated into a target enrollment number of 364 individuals.

2.2. Participants. Details of the study have been reported elsewhere [27]. Eligible participants were aged $\geq 35$ years and having hypertension for at least 12 months. Participants who could not communicate effectively with the study personnel or provide informed consent were excluded. During the enrollment period, we confirmed participants' hypertension diagnosis through a medication inventory.

We mainly recruited subjects for this study through a community health center, which is a public medical center providing medical and public health services to civilians. A total of 890 hypertensive patients were registered in the community health center. Physicians screened the registered patients for eligibility for the study, out of which 143 patients without contact information were excluded. Of the remaining 747 patients, 456 patients met the inclusion criteria and were invited to participate in this study via telephone. As some hypertensive patients may have not attended the health clinic and were not registered, we also recruited subjects through word-of-mouth and put up a poster in the community to create awareness about the study.

Briefly, 523 individuals were invited to participate in the study. Of these, 456 were registered patients. An additional 41 individuals were recruited by referral from study participants who were already recruited, and 26 joined after viewing a poster advertisement in the community. Eligibility was assessed by the physicians at the study sites. After exclusion or drop out from the study, a final study population of 318 patients (289 recruited from registration, 17 from referral, and 12 from the poster advertisement) completed the questionnaire.

2.3. Instruments. The face-to-face questionnaire was structured with inspiration from the National Center for Complementary and Alternative Medicine, literature review, and discussion with public health professionals.

Questions were divided into three domains: sociodemographic characteristics, hypertension-related information, and CAM use. Sociodemographic data included gender, age, educational level ( $\leq 6$ and $>6$ years), annual family income $(<500,000$ and $\geq 500,000$ yuan), and marital status. Hypertension-related questions assessed self-reported type and duration of hypertension and perceived health status (very good, good, fair, poor, and very poor). Questions related to CAM were related to the type of CAM and its use in the past 12 months, whether it was specifically used for hypertension, perceived effectiveness of the CAM, and the source of information about CAM.

The questionnaire also asked about the use of over 20 different CAM therapies within the past 12 months. For these analyses, the therapies were collapsed into five modalities according to the National Center for Complementary and Alternative Medicine and other related literature [21, 22]. The modalities were as follows: alternative medical systems (e.g., traditional Chinese medicine, acupuncture, and cupping), mind-body medicine (e.g., prayer, relaxation, tai Chi, yangge, and qigong), manipulative and body-based methods (e.g., spinal manipulation and massage), natural products (e.g., herbal medicine, probiotics, omega 3s, and fish oil), and vitamin/dietary supplements (e.g., vitamin C, vitamin $\mathrm{B} / \mathrm{B} 12$, multivitamin, calcium supplements, and other dietary supplements).

2.4. Data Management and Statistical Analysis. Data were double entered and crosschecked using Epi Info, version 6. All statistical analyses were performed using IBM SPSS version 19 (SPSS Inc., Chicago, IL, USA). 
TABLE 1: Characteristics of respondents: users and nonusers of CAM.

\begin{tabular}{|c|c|c|c|c|}
\hline Characteristics & $\begin{array}{c}\text { Total }(100 \%) \\
n=318\end{array}$ & $\begin{array}{c}\text { CAM users } \\
(74.2 \%) n=236\end{array}$ & $\begin{array}{c}\text { Non-CAM users } \\
(25.8 \%) n=82\end{array}$ & $P$ value \\
\hline Mean age, years (SD) & $62.9(9.8)$ & $63.0(9.7)$ & $62.9(9.9)$ & 0.997 \\
\hline Gender & & & & $0.027^{*}$ \\
\hline Males & $90(28.3)$ & $59(25.0)$ & $31(37.8)$ & \\
\hline Females & $228(71.7)$ & $177(75.0)$ & $51(62.2)$ & \\
\hline Marital status & & & & 0.630 \\
\hline Single & $6(1.9)$ & $4(1.7)$ & $2(2.4)$ & \\
\hline Married/common law & $281(88.4)$ & $207(87.7)$ & $74(90.2)$ & \\
\hline Widowed/separated/divorced & $31(9.7)$ & $25(10.6)$ & $6(7.3)$ & \\
\hline Level of education & & & & 0.296 \\
\hline$\leq 6$ years & $222(69.8)$ & $169(71.6)$ & $53(64.6)$ & \\
\hline$>6$ years & $96(30.2)$ & $67(28.4)$ & $29(35.4)$ & \\
\hline Annual family income & & & & 0.600 \\
\hline$<50,000$ yuan & $309(97.2)$ & $230(97.5)$ & $79(96.3)$ & \\
\hline$\geq 50,000$ yuan & $9(2.8)$ & $6(2.5)$ & $3(3.7)$ & \\
\hline Self-rated health & & & & 0.498 \\
\hline Very good & $8(2.5)$ & $8(3.4)$ & $0(0.0)$ & \\
\hline Good & $71(22.3)$ & $45(19.1)$ & $26(31.7)$ & \\
\hline Fair & $153(48.1)$ & $118(50.0)$ & $35(42.7)$ & \\
\hline Poor & $78(24.5)$ & $59(25.0)$ & $19(23.2)$ & \\
\hline Very poor & $7(2.2)$ & $5(2.1)$ & $2(2.4)$ & \\
\hline Mean duration of hypertension diagnosis, years (SD) & $8.2(7.1)$ & $8.2(7.3)$ & $8.2(6.5)$ & 0.364 \\
\hline
\end{tabular}

${ }^{*}$ Statistical significance of difference, $P \leq 0.05$.

Descriptive statistics included sample size, percentages, and means. Differences in demographic and health characteristics between users and nonusers of CAM and differences in CAM modalities between female and male participants were tested using the chi-square test and Fisher's exact test. A logistic regression model was used for the analysis of CAM use with age, gender, duration of hypertension, selfrated health, and annual family income as variables. The significance threshold for all tests was 0.05 .

2.5. Ethical Considerations and Treatment. Approval for this study was given by the ethical review board at Waseda University. Informed consent was obtained from all the participants prior to data collection. An information sheet describing the study was available for all participants. The front page of the questionnaire stated that all the data would kept confidential and that the results would be presented at a group level. Participants were informed that they could stop the interview at any time and decline to answer the questions without giving a reason. At the end of the study, all participants were given a small gift in return for their participation.

\section{Results}

3.1. Characteristics of Sample. Of the 318 respondents, 228 $(71.7 \%)$ were female and $90(28.3 \%)$ were male. The mean age of participants was $62.9(\mathrm{SD}=9.8)$ years. An overall statistical description of the CAM users and nonusers $(n=318)$ is shown in Table 1. CAM users did not differ significantly from non-CAM users either by age $(P=0.997)$, marital status $(P=0.630)$, education $(P=0.296)$, income $(P=0.600)$, self-rated health $(P=0.498)$, or duration of hypertension $(P=0.364)$; they differed only by gender $(P=0.027)$.

3.2. Prevalence, Types of Cam Use, and Its Associated Factors. The results showed that $74.2 \%(236 / 318)$ of patients used a form of CAM in the past 12 months; $19.1 \%, 18.6 \%$, and $36.5 \%$ of patients used one type, two types, and more than two types of CAM, respectively. The types and modes of CAM used by participants are presented in Table 2. Few differences were observed when comparing CAM modalities. Only mind-body medicine differed by gender $(P=0.012)$. Traditional Chinese medicine, cupping, relaxation, herbal medicine, and calcium supplements were the most frequently used. Logistic regression analysis using age, gender, duration of hypertension, self-rated health, and annual family income showed a significantly higher prevalence of CAM use in female than in male participants (adjusted OR 1.82, 95\% CI $1.09,3.11)$.

3.3. Purposes for Using CAM. Approximately 13.1\% (31) of the 236 CAM users used CAM specifically to treat their hypertension, accounting for $9.7 \%$ of the full sample (318). 
TABLE 2: Use of CAM by gender.

\begin{tabular}{|c|c|c|c|c|}
\hline & Males $(\%) n=90$ & Females $(\%) n=228$ & Total $(\%) n=318$ & $P$ value \\
\hline Any CAM use & $59(65.6)$ & $177(77.6)$ & $236(74.2)$ & \\
\hline Any CAM use, excluding prayer & $58(64.4)$ & $177(77.6)$ & $235(73.9)$ & \\
\hline Alternative medical systems & & & & 0.744 \\
\hline Traditional Chinese medicine & $18(20.0)$ & $58(25.4)$ & $76(23.9)$ & \\
\hline Acupuncture & $5(0.56)$ & $24(10.5)$ & $29(9.1)$ & \\
\hline Cupping & $19(21.1)$ & $74(32.5)$ & $93(29.2)$ & \\
\hline Mind-body medicine & & & & $0.012^{*}$ \\
\hline Prayer & $5(0.56)$ & $10(4.4)$ & $15(4.7)$ & \\
\hline Relaxation & $31(34.4)$ & $86(37.7)$ & $117(36.8)$ & \\
\hline Ta chi & $2(2.2)$ & $1(0.4)$ & $3(0.9)$ & \\
\hline Qigong & $2(2.2)$ & $3(1.3)$ & $5(1.5)$ & \\
\hline Yangge & $1(1.1)$ & $32(14.0)$ & $33(10.3)$ & \\
\hline Manipulative/body based & & & & 0.544 \\
\hline Spinal manipulation & $2(2.2)$ & $4(1.8)$ & $6(1.9)$ & \\
\hline Massage therapy & $2(2.2)$ & $13(5.7)$ & $15(4.7)$ & \\
\hline Natural products & & & & 0.713 \\
\hline Herbal medicine & $14(15.6)$ & 45 (19.7) & $59(18.5)$ & \\
\hline Probiotics & $2(2.2)$ & $13(5.7)$ & $15(4.7)$ & \\
\hline Omega $3 \mathrm{~s}$ & $0(0.0)$ & $1(0.4)$ & $1(0.3)$ & \\
\hline Fish oil & $2(2.2)$ & $6(2.6)$ & $8(2.5)$ & \\
\hline Vitamin/dietary supplements & & & & 0.316 \\
\hline Vitamin C & $8(8.9)$ & $20(8.8)$ & $28(8.8)$ & \\
\hline Vitamin $\mathrm{B} / \mathrm{B} 12$ & $4(4.4)$ & $33(14.5)$ & 37 (11.6) & \\
\hline Multivitamins & $3(3.3)$ & $7(3.1)$ & $10(3.1)$ & \\
\hline Calcium supplements & $30(33.3)$ & $89(39.0)$ & $119(37.4)$ & \\
\hline Other dietary supplements & $4(4.4)$ & $12(5.3)$ & $16(5.0)$ & \\
\hline
\end{tabular}

* Statistical Significance of Difference $P \leq 0.05$.

Table 3 showed that major purposes of CAM use as reported by the respondents included treatment for other medical conditions $(288 / 674,42.7 \%)$ and promoting general health (229/674, 34.0\%). Only 7.3\% (49/674) of total CAM use was reported to be for hypertension treatment. Of those responses, $30.1 \%$ cited calcium supplements use for general health. About $32.7 \%$ of responses citing hypertension as a purpose mentioned traditional Chinese medicine, and $28.6 \%$ mentioned herbal medicine. About $26.0 \%$ of responses citing other medical conditions as a purpose mentioned cupping, and $76.3 \%$ citing improving mood mentioned relaxation. The use of alternative medical system $(P=0.002)$, mind-body medicine $(P<0.001)$, natural products $(P<0.001)$, and vitamin/dietary supplements $(P=0.031)$ differed in the reported purposes of CAM use.

3.4. Information Sources for CAM. Comparisons of CAM modalities against information sources for CAM are provided in Table 4 . There was a statistically significant association between CAM modalities and information sources $\left(\chi^{2}=\right.$ 81.373, $P<0.001)$. Family/relatives, doctors, and patients themselves were the three main information sources for CAM. Specifically, $42.6 \%$ of the use of traditional Chinese medicine, herbal medicine, and acupuncture was suggested by doctors, and $79.7 \%$ of the use of cupping, relaxation, and calcium supplements was suggested by family/relatives or just by patients themselves.

3.5. Perceived Effectiveness of CAM. Table 5 presents perceived effectiveness of CAM as per CAM modalities. Perceived effectiveness significantly differed with respect to CAM modality $\left(\chi^{2}=39.371, P<0.001\right)$. More than $70 \%$ of the respondents were able to perceive the effectiveness of alternative medical systems, mind-body medicine, and manipulative/body-based therapies. According to the responses, traditional Chinese medicine (59.2\%), herb medicine $(64.9 \%)$, cupping $(81.5 \%)$, massage $(86.7 \%)$, spinal manipulation $(83.3 \%)$, and prayer $(71.4 \%)$ were reported as the most effective CAM.

\section{Discussion}

Our analyses indicated a higher prevalence of CAM use (74.2\%) in the current hypertension population than that in population studies conducted in the USA (69.5\%) [21] and UK (43.1\%) [22]. Of the 236 CAM users, $13.1 \%$ reported using any CAM for treating hypertension, which is higher than the results of the USA study (7.8\%) [21]. The prevalence of 
TABle 3: Purposes for which CAM was used ${ }^{\triangle}$.

\begin{tabular}{|c|c|c|c|c|c|c|}
\hline & \multicolumn{5}{|c|}{ Purposes of using CAM } & \multirow[b]{2}{*}{$P$ value } \\
\hline & $\begin{array}{c}\text { General } \\
\text { health }\end{array}$ & $\begin{array}{c}\text { Hypertension } \\
\text { treatment }\end{array}$ & $\begin{array}{l}\text { Treatment of other } \\
\text { medical conditions }\end{array}$ & $\begin{array}{c}\text { Mood } \\
\text { improvement }\end{array}$ & Other & \\
\hline Alternative medical systems $(n, \%)$ & & & & & & $0.002^{*}$ \\
\hline Traditional Chinese medicine & $7(3.1)$ & $16(32.7)$ & $50(17.4)$ & $2(2.2)$ & $1(9.1)$ & \\
\hline Acupuncture & $5(2.2)$ & $0(0.0)$ & $22(7.6)$ & $2(2.2)$ & $0(0.0)$ & \\
\hline Cupping & $10(4.4)$ & $2(4.1)$ & $75(26.0)$ & $4(4.3)$ & $1(9.1)$ & \\
\hline Mind-body medicine $(n, \%)$ & & & & & & $<0.001^{*}$ \\
\hline Prayer & $4(1.7)$ & $4(8.2)$ & $1(0.3)$ & $4(4.3)$ & $2(18.2)$ & \\
\hline Relaxation & $35(15.3)$ & $5(10.2)$ & $4(1.4)$ & $71(76.3)$ & $0(0.0)$ & \\
\hline Ta chi & $2(0.9)$ & $0(0.0)$ & $0(0.0)$ & $1(1.1)$ & $0(0.0)$ & \\
\hline Qigong & $3(1.3)$ & $0(0.0)$ & $1(0.3)$ & $0(0.0)$ & $0(0.0)$ & \\
\hline Yangge & $23(10.0)$ & $0(0.0)$ & $0(0.0)$ & $10(10.8)$ & $0(0.0)$ & \\
\hline Manipulative/body based $(n, \%)$ & & & & & & 0.727 \\
\hline Spinal manipulation & $3(1.3)$ & $0(0.0)$ & $2(0.7)$ & $1(1.1)$ & $0(0.0)$ & \\
\hline Massage therapy & $7(3.1)$ & $0(0.0)$ & $7(2.4)$ & $1(1.1)$ & $0(0.0)$ & \\
\hline Natural products $(n, \%)$ & & & & & & $<0.001^{*}$ \\
\hline Herbal medicine & $4(1.7)$ & $14(28.6)$ & $39(13.5)$ & $0(0.0)$ & $2(18.2)$ & \\
\hline Probiotics & $12(5.2)$ & $0(0.0)$ & $1(0.3)$ & $0(0.0)$ & $0(0.0)$ & \\
\hline Omega 3s & $1(0.4)$ & $2(4.1)$ & $1(0.3)$ & $0(0.0)$ & $0(0.0)$ & \\
\hline Fish oil & $4(1.7)$ & $0(0.0)$ & $0(0.0)$ & $0(0.0)$ & $2(18.2)$ & \\
\hline Vitamin/dietary supplements $(n, \%)$ & & & & & & $0.031^{*}$ \\
\hline Vitamin C & $11(4.8)$ & $1(2.0)$ & $14(4.9)$ & $0(0.0)$ & $2(18.2)$ & \\
\hline Vitamin B/B12 & $12(5.2)$ & $2(4.1)$ & $21(7.3)$ & $0(0.0)$ & $1(9.1)$ & \\
\hline Multivitamins & $7(3.1)$ & $0(0.0)$ & $3(1.0)$ & $0(0.0)$ & $0(0.0)$ & \\
\hline Calcium supplements & $69(30.1)$ & $1(2.0)$ & $45(15.6)$ & $0(0.0)$ & $2(18.2)$ & \\
\hline Other dietary supplements & $10(4.4)$ & $2(4.1)$ & $2(0.7)$ & $1(1.1)$ & $0(0.0)$ & \\
\hline Total $(n)$ & 229 & 49 & 288 & 97 & 11 & \\
\hline
\end{tabular}

*Statistical Significance of Difference $P \leq 0.05$.

${ }^{\triangle}$ Multiple responses given.

A total of 674 CAM uses were reported by 236 CAM users.

TABLE 4: Information source for $\mathrm{CAM}^{\triangle}$.

\begin{tabular}{lcccccccc}
\hline & Family/relatives & Friends/colleagues & Internet & $\begin{array}{c}\text { Book or } \\
\text { magazine }\end{array}$ & $\begin{array}{c}\text { Radio or } \\
\text { TV }\end{array}$ & Doctor & CAM user & $\begin{array}{c}\text { Patients } \\
\text { themselves }\end{array}$ \\
\hline $\begin{array}{l}\text { Alternative medical } \\
\text { systems }\end{array}$ & $54(27.69)$ & $8(4.1)$ & $1(0.51)$ & $0(0.00)$ & $1(0.51)$ & $48(24.62)$ & $2(1.03)$ & $81(41.54)$ \\
$\begin{array}{l}\text { Mind-body medicine } \\
\text { Manipulative/body }\end{array}$ & $44(27.50)$ & $15(9.38)$ & $0(0.00)$ & $1(0.63)$ & $6(3.75)$ & $6(3.75)$ & $2(1.25)$ & $86(53.75)$ \\
based & $7(33.33)$ & $1(4.76)$ & $0(0.00)$ & $0(0.00)$ & $1(4.76)$ & $3(14.29)$ & $0(0.00)$ & $9(42.86)$ \\
$\begin{array}{l}\text { Natural products } \\
\begin{array}{l}\text { Vitamin/dietary } \\
\text { supplements }\end{array}\end{array}$ & $20(24.69)$ & $2(2.47)$ & $0(0.00)$ & $0(0.00)$ & $0(0.00)$ & $33(40.74)$ & $0(0.00)$ & $26(32.10)$ \\
\hline
\end{tabular}

${ }_{{ }^{\circ}}$ Multiple responses given.

CAM use for hypertension treatment in our study is similar to that reported from another hypertension study in China [20]. However, the results of these studies are not directly comparable with this study because of differences in the definition of CAM use, study population, and study period.
Previous population studies have shown CAM use to be significantly associated with educational status, gender, wealth, and health status $[8,12-15]$. However, no significant differences of income, age, duration of hypertension, education, or health status were observed between CAM and 
TABLE 5: Perceived effectiveness of $\mathrm{CAM}^{\triangle}$.

\begin{tabular}{|c|c|c|c|c|}
\hline & Not effective & A little effective & Effective & Very effective \\
\hline Alternative medical systems & $16(8.12)$ & $45(22.84)$ & $100(50.8)$ & $36(18.27)$ \\
\hline Mind-body medicine & $11(6.59)$ & $34(20.4)$ & $85(50.9)$ & $37(22.16)$ \\
\hline Manipulative/body based & $1(4.76)$ & $2(9.52)$ & $15(71.4)$ & $3(14.3)$ \\
\hline Natural products & $13(16.25)$ & $21(26.25)$ & $36(45.00)$ & $10(12.5)$ \\
\hline Vitamin/dietary supplements & $40(19.6)$ & $62(30.39)$ & $79(38.73)$ & $23(11.27)$ \\
\hline
\end{tabular}

${ }^{\triangle}$ Multiple responses given.

non-CAM users in the current sample. Similar findings were also reported in other studies about CAM use in patients with chronic diseases [22, 28, 29]. One might speculate that CAM users in the hypertension clinic do not fit the demographic patterns in population studies. However, the definitions of CAM use, study population characteristics, and representation of the samples varied among studies, which may contribute to the difference in the results. Our study results showed that women were more likely to use CAM than men (or 1.82, 95\% CI 1.09, 3.11). However, there is conflicting evidence about gender differences in CAM use [22, 28, 29]. These conflicting findings suggest that the association of CAM use with sociodemographic characteristics is complex, requiring further exploration.

Our results revealed that $76.7 \%$ of CAM use was for general health $(229 / 674,34.0 \%)$ and other medical conditions $(288 / 674,42.7 \%$ ) (Table 3 ). Only $7.3 \%$ of CAM use was reported to be for hypertension treatment. Among the responses reporting use for hypertension treatment, traditional Chinese medicine and herbal medicine constituted $32.7 \%$ and $28.6 \%$, respectively. Although prayer and relaxation therapies are usually not recommended as part of treatment for hypertension [22], these were used for hypertension treatment by $10.2 \%$ and $8.2 \%$ of the participants, respectively. The widespread use of prayer and relaxation in hypertension patients may be because hypertension is often comorbid with depression/anxiety [30]. However, to our knowledge, no study has examined the relationship between relaxation therapy use and depression in hypertension patients. Exploring these associations may help us to understand better the use of prayer and relaxation in hypertension treatment.

The effects of traditional Chinese CAM like qigong, tai chi, and herbal medicine are well recognized by clinicians and the general population [16]. CAM is commonly used by Chinese to promote general health and to treat or prevent medical conditions. To some extent, this can explain why family/relatives, doctors, and patients themselves are the three main information sources for CAM as well as the high level of satisfaction with these CAM.

Our study showed that nearly half of the use of traditional Chinese medicine, herbal medicine, and acupuncture was suggested by doctors, and over three quarters of the use of cupping, relaxation, and calcium supplements was suggested by family/relatives or by the participants themselves. It seems that professional therapies were introduced mainly by doctors. However, common and less professional therapies may be used mainly because of the patients' surroundings.
According to the responses, traditional Chinese medicine (59.2\%), herb medicine (64.9\%), cupping (81.5\%), massage $(86.7 \%)$, spinal manipulation $(83.3 \%)$, and prayer $(71.4 \%)$ were reported as the most effective CAM. Since there is little literature about the perceived effectiveness of CAM use, it is difficult to compare these results with other studies.

\section{Limitations}

The findings of this study should be interpreted with caution. As the study followed a cross-sectional design, no causal determinants of CAM use can be ascertained. The definition of CAM modalities in this study may differ from other studies, resulting in comparison difficulties. The data in this study were obtained through a self-report questionnaire, and recall bias is inevitable to some extent as participants had to report their use of CAM over the past 12 months. Selection bias may have occurred. Out of the 890 registered patients, 289 participated in this survey. The subjects who agreed to participate may be different from those who did not participate. Notably, $9 \%$ of participants were recruited through poster and word-of-mouth from study participants. There may be a limited self-selection bias. There is over representation of females $(71.7 \%)$ which may lead to bias, especially because females were found to use CAM more than males. It is also important to acknowledge that our study did not reach the projected sample size in the power calculations; this may limit the power of this study. Finally, this study is a community-based survey and cannot represent the national population.

\section{Conclusions}

This paper is the first survey that fully describes the use of CAM in hypertension patients in China. Given the high prevalence of CAM use in the hypertension population and the poor control of hypertension, it is important to understand the use of CAM as a form of self-care among hypertension patients. So far, there is little information about the use of CAM in the hypertension population in China. Further research is needed to understand better the CAM use in patients with hypertension and other people.

\section{Conflict of Interests}

The authors declare that they have no competing interests. 


\section{References}

[1] P. M. Kearney, M. Whelton, K. Reynolds, P. Muntner, P. K. Whelton, and J. He, "Global burden of hypertension: analysis of worldwide data," The Lancet, vol. 365, no. 9455, pp. 217-223, 2005.

[2] C. M. Lawes, S. V. Hoorn, and A. Rodgers, "Global burden of blood-pressure-related disease," The Lancet, vol. 371, no. 9623, pp. 1513-1518, 2008.

[3] J. Yang, F. Lu, C. Zhang et al., "Prevalence of prehypertension and hypertension in a Chinese rural area from 1991 to 2007," Hypertension Research, vol. 33, no. 4, pp. 331-337, 2010.

[4] G.-H. Dong, Z.-Q. Sun, X.-Z. Zhang et al., "Prevalence, awareness, treatment \& control of hypertension in rural Liaoning province, China," Indian Journal of Medical Research, vol. 128, no. 2, pp. 122-127, 2008.

[5] A. V. Chobanian, G. L. Bakris, H. R. Black et al., "The seventh report of the joint National Committee on Prevention, Detection, Evaluation, and Treatment of high blood pressure: the JNC 7 report," Journal of the American Medical Association, vol. 289, no. 19, pp. 2560-2572, 2003.

[6] J. Barnes, "Quality, efficacy and safety of complementary medicines: fashions, facts and the future. Part I. Regulation and quality," British Journal of Clinical Pharmacology, vol. 55, no. 3, pp. 226-233, 2003.

[7] D. Su and L. Li, "Trends in the use of complementary and alternative medicine in the United States: 2002-2007," Journal of Health Care for the Poor and Underserved, vol. 22, no. 1, pp. 296-310, 2011.

[8] J. Adams, D. Sibbritt, and A. F. Young, "A longitudinal analysis of older Australian women's consultations with complementary and alternative medicine (CAM) practitioners, 1996-2005," Age and Ageing, vol. 38, no. 1, pp. 93-99, 2009.

[9] P. Harris and R. Rees, "The prevalence of complementary and alternative medicine use among the general population: a systematic review of the literature," Complementary Therapies in Medicine, vol. 8, no. 2, pp. 88-96, 2000.

[10] N. Maha and A. Shaw, "Academic doctors' views of complementary and alternative medicine (CAM) and its role within the NHS: an exploratory qualitative study," BMC Complementary and Alternative Medicine, vol. 7, article 17, 2007.

[11] D. W. Sibbritt, J. Adams, and A. F. Young, "A longitudinal analysis of mid-age women's use of Complementary and Alternative Medicine (CAM) in Australia, 1996-1998," Women and Health, vol. 40, no. 4, pp. 41-56, 2004.

[12] J. Park, "Use of alternative health care," Health Reports, vol. 16, no. 2, pp. 39-42, 2004.

[13] W. J. Millar, "Patterns of use - alternative health care practitioners," Health Reports, vol. 13, no. 1, pp. 9-21, 2001.

[14] D. Mclaughlin, J. Adams, D. Sibbritt, and C.-W. Lui, "Sex differences in the use of complementary and alternative medicine in older men and women," Australasian Journal on Ageing, vol. 31, no. 2, pp. 78-82, 2012.

[15] B. McFarland, D. Bigelow, B. Zani, J. Newsom, and M. Kaplan, "Complementary and alternative medicine use in Canada and the United States," American Journal of Public Health, vol. 92, no. 10, pp. 1616-1618, 2002.

[16] World Health Organization, Traditional Medicine Strategy 2002-2005, WHO, Geneva, Switzerland, 2002.

[17] G. Y. Yeh, C. Wang, P. M. Wayne, and R. S. Phillips, “The effect of Tai Chi exercise on blood pressure: a systematic review," Preventive Cardiology, vol. 11, no. 2, pp. 82-89, 2008.
[18] X. Guo, B. Zhou, T. Nishimura, S. Teramukai, and M. Fukushima, "Clinical effect of Qigong practice on essential hypertension: a meta-analysis of randomized controlled trials," Journal of Alternative and Complementary Medicine, vol. 14, no. 1, pp. 27-37, 2008.

[19] J. Wang and X. Xiong, "Control strategy on hypertension in Chinese medicine," Evidence-based Complementary and Alternative Medicine, vol. 2012, Article ID 284847, 6 pages, 2012.

[20] D. Gu, K. Reynolds, X. Wu et al., "Prevalence, awareness, treatment, and control of hypertension in China," Hypertension, vol. 40, no. 6, pp. 920-927, 2002.

[21] R. A. Bell, C. K. Suerken, J. G. Grzywacz, W. Lang, S. A. Quandt, and T. A. Arcury, "CAM use among older adults age 65 or older with hypertension in the United States: general use and disease treatment," Journal of Alternative and Complementary Medicine, vol. 12, no. 9, pp. 903-909, 2006.

[22] F. Gohar, S. M. Greenfield, D. Gareth Beevers, G. Y. H. Lip, and K. Jolly, "Self-care and adherence to medication: a survey in the hypertension outpatient clinic," BMC Complementary and Alternative Medicine, vol. 8, no. 1, article 4, 2008.

[23] G. B. W. Lee, T. C. Charn, Z. H. Chew, and T. P. Ng, "Complementary and alternative medicine use in patients with chronic diseases in primary care is associated with perceived quality of care and cultural beliefs," Family Practice, vol. 21, no. 6, pp. 654-660, 2004.

[24] L. Hooper, R. L. Thompson, R. A. Harrison et al., "Risks and benefits of omega 3 fats for mortality, cardiovascular disease, and cancer: systematic review," British Medical Journal, vol. 332, no. 7544, pp. 752-755, 2006.

[25] L. Chagan, D. Bernstein, J. W. M. Cheng et al., "Use of biological based therapy in patients with cardiovascular diseases in a university-hospital in New York City," BMC Complementary and Alternative Medicine, vol. 5, article 4, 2005.

[26] J. Adams, D. Sibbritt, A. Broom et al., "A comparison of complementary and alternative medicine users and use across geographical areas: a national survey of 1,427 women," BMC Complementary and Alternative Medicine, vol. 11, article 85, 2011.

[27] H. H. Hu, G. Li, and T. Arao, "Prevalence rates of self-care behaviors and related factors in a rural hypertension population: a questionnaire survey," International Journal of Hypertension, vol. 2013, Article ID 526949, 8 pages, 2013.

[28] K. Manya, B. Champion, and T. Dunning, "The use of complementary and alternative medicine among people living with diabetes in Sydney," BMC Complementary and Alternative Medicine, vol. 12, article 2, 2012.

[29] O. C. Amira and N. U. Okubadejo, "Frequency of complementary and alternative medicine utilization in hypertensive patients attending an urban tertiary care centre in Nigeria," BMC Complementary and Alternative Medicine, vol. 7, article 30, 2007.

[30] M. A. Krousel-Wood and E. D. Frohlich, "Hypertension and depression: coexisting barriers to medication adherence," Journal of Clinical Hypertension, vol. 12, no. 7, pp. 481-486, 2010. 


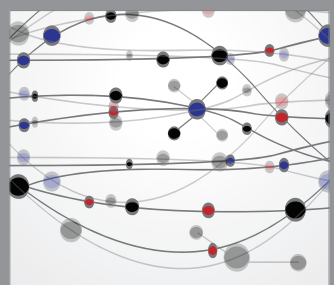

The Scientific World Journal
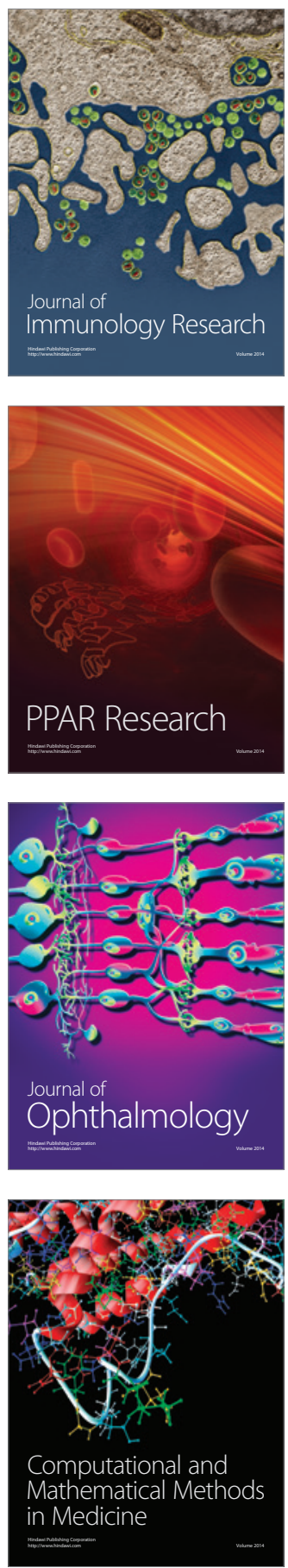

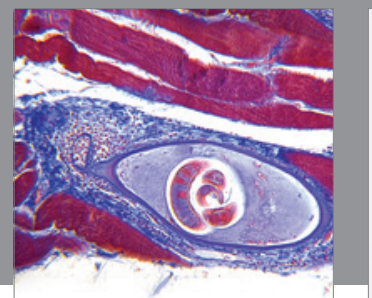

Gastroenterology

Research and Practice
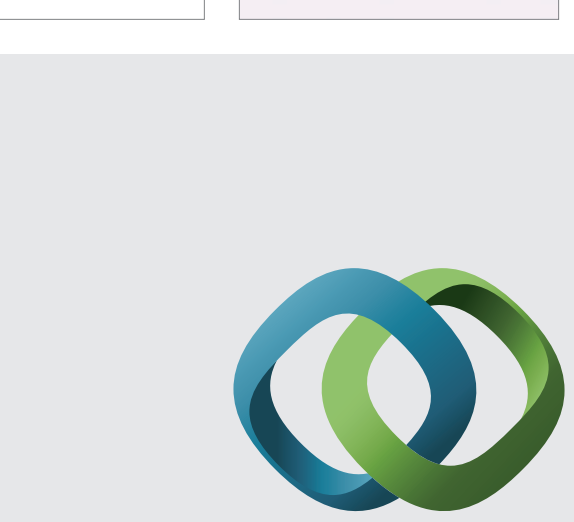

\section{Hindawi}

Submit your manuscripts at

http://www.hindawi.com
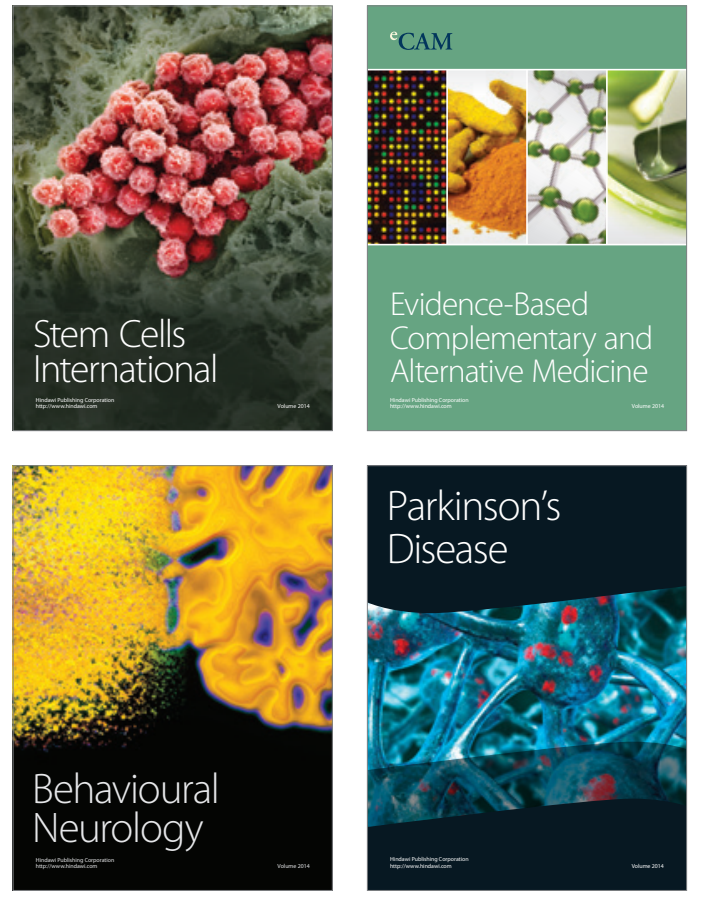
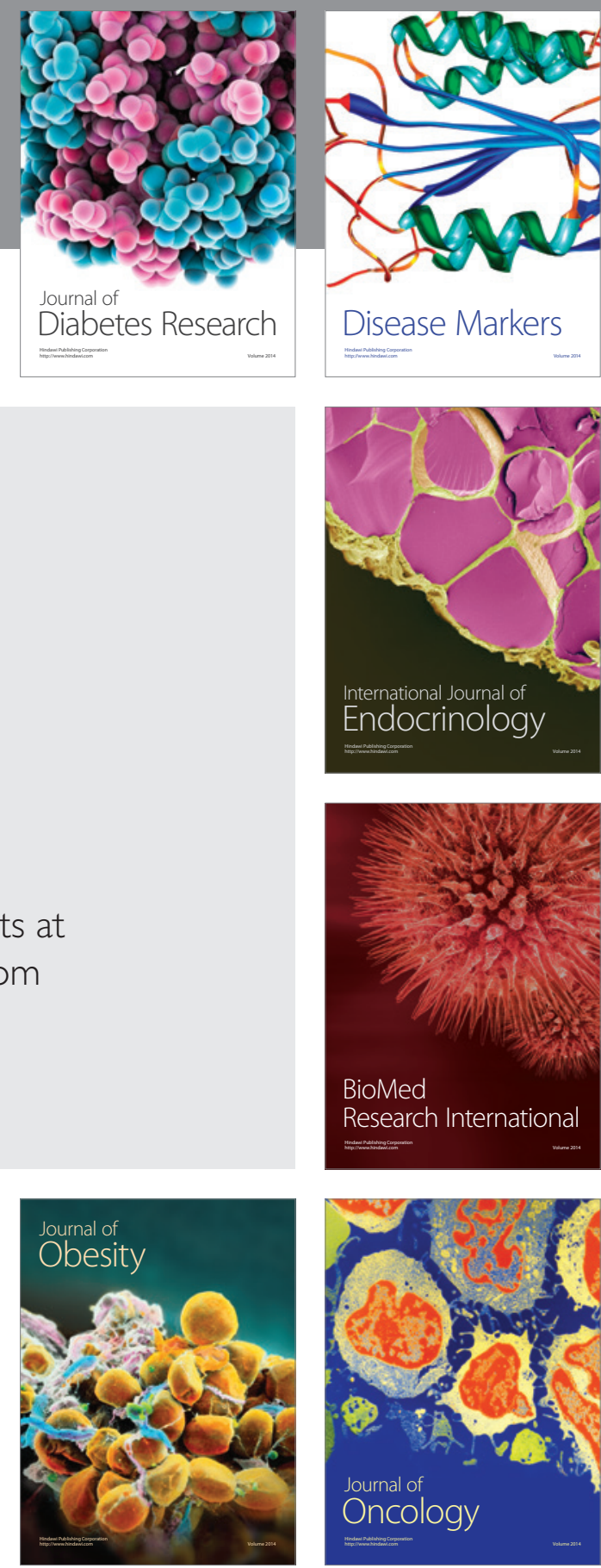

Disease Markers
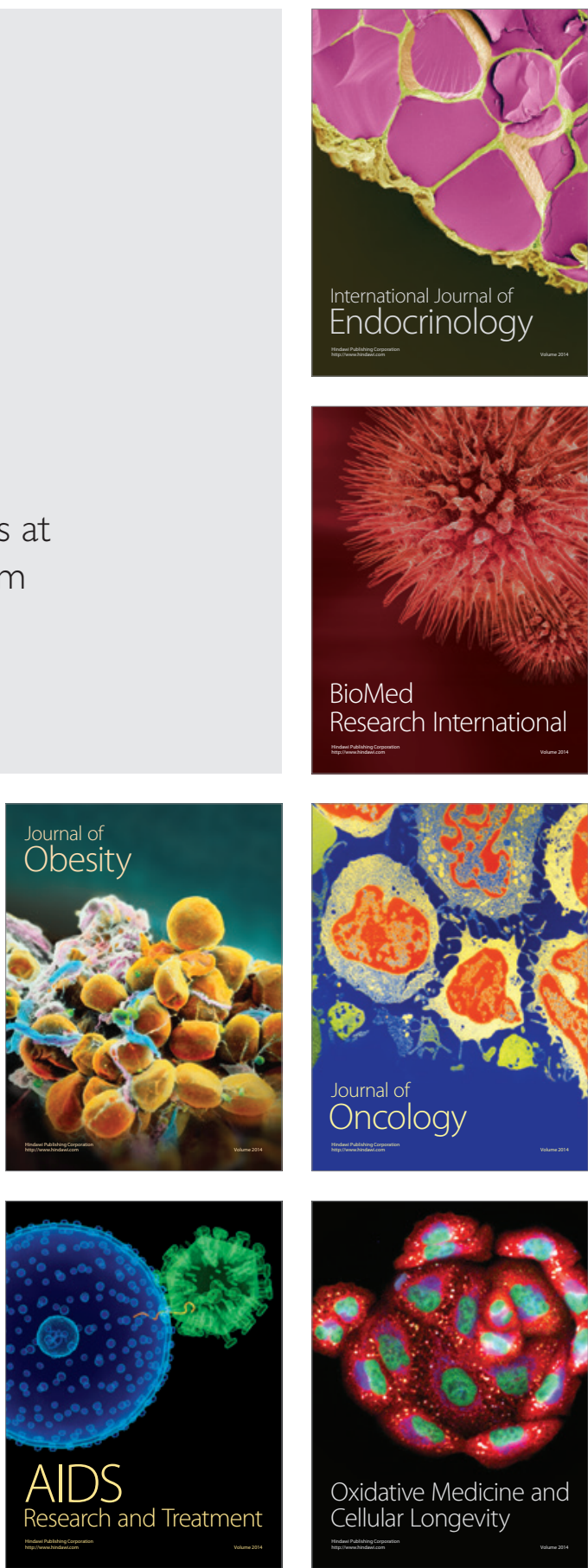